\title{
IMPROVED INEQUALITIES FOR TRIGONOMETRIC FUNCTIONS VIA DIRICHLET AND ZETA FUNCTIONS
}

\author{
D. AHARONOV AND U. EliAS
}

Abstract. The article discusses several improvements of well known inequalities for trigonometric functions. We utilize the monotonicity of the Riemann zeta function, as well as the Dirichlet eta, beta and lambda functions, to shorten the proofs of known inequalities for trigonometric functions, and to obtain new ones.

Mathematics subject classification (2010): 26D05.

Keywords and phrases: Trigonometric inequalities, Becker-Stark inequality, Redheffer inequality, Dirichlet functions.

\section{REFERENCES}

[1] Á. BARICZ, Generalized Bessel Functions of the First Kind, Lecture Notes in Mathematics, Volume 1994, Springer Verlag, Berlin, Heidelberg, 2010.

[2] M. BECKER AND E. STARK, On a hierarchy of quolynomial inequalities for $\tan x$, Univ. Beograd. Publ. Elektrotehn. Fak. Ser. Mat. Fiz. 620 (1978), 133-138.

[3] ChaO-Ping Chen and Feng QI, A double inequality for remainder of power series of tangent function, Tamkang J. of Mathematics 34 (2003), 351-355.

[4] ChaO-Ping Chen And Feng QI, Inequalities of some trigonometric functions, Univ. Beograd. Publ. Elektrotehn. Fak. Ser. Mat. 15 (2004), 71-78.

[5] Feng Qi, Da-Wei Niu And Bai-Ni Guo, Refinements, Generalizations and Applications of Jordan's inequality and related problems, J. of Inequalities and Applications 2009 (2009), Article ID 271923, 52 pages, doi:10.1155/2009/271293.

[6] R. RedhefFer, Problem 5642, The American Math. Monthly 76 (1969), 1153-1154.

[7] J. Spanier and Keith B. Oldham, An atlas of functions, Hemisphere Publishing, Washington, 1987.

[8] LING ZHU AND JINJU SUn, Six new Redheffer-type inequalities for circular and hyperbolic functions, Computers and Mathematics with Applications 56 (2008), 522-529. 